NASA/TM-1999-209143

ARL-TR-1976
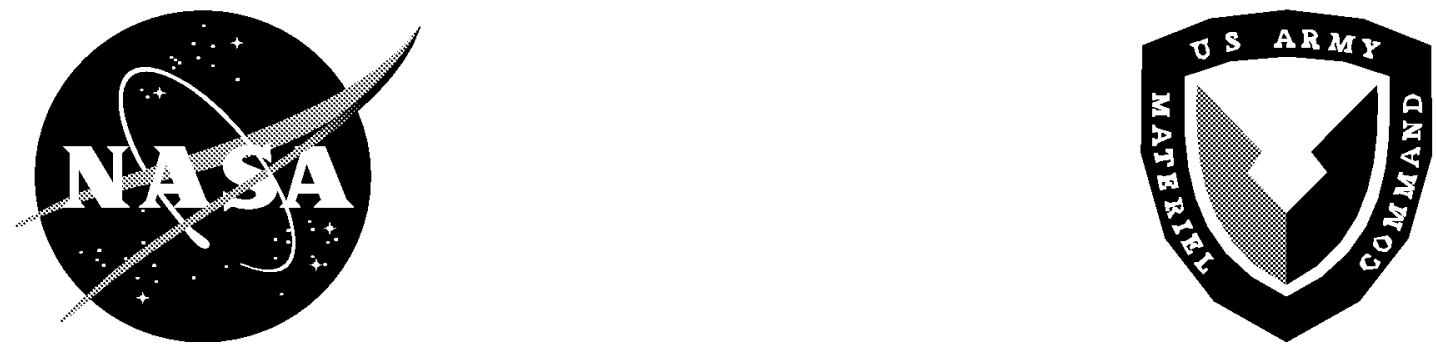

\title{
An Overview of Landing Gear Dynamics
}

Jocelyn I. Pritchard

U.S. Army Research Laboratory

Vehicle Technology Directorate

Langley Research Center, Hampton, Virginia 


\section{The NASA STI Program Office ... in Profile}

Since its founding, NASA has been dedicated to the advancement of aeronautics and space science. The NASA Scientific and Technical Information (STI) Program Office plays a key part in helping NASA maintain this important role.

The NASA STI Program Office is operated by Langley Research Center, the lead center for NASA's scientific and technical information. The NASA STI Program Office provides access to the NASA STI Database, the largest collection of aeronautical and space science STI in the world. The Program Office is also NASA's institutional mechanism for disseminating the results of its research and development activities. These results are published by NASA in the NASA STI Report Series, which includes the following report types:

- TECHNICAL PUBLICATION. Reports of completed research or a major significant phase of research that present the results of NASA programs and include extensive data or theoretical analysis. Includes compilations of significant scientific and technical data and information deemed to be of continuing reference value. NASA counterpart of peer-reviewed formal professional papers, but having less stringent limitations on manuscript length and extent of graphic presentations.

- TECHNICAL MEMORANDUM. Scientific and technical findings that are preliminary or of specialized interest, e.g., quick release reports, working papers, and bibliographies that contain minimal annotation. Does not contain extensive analysis.

- CONTRACTOR REPORT. Scientific and technical findings by NASA-sponsored contractors and grantees.
- CONFERENCE PUBLICATION. Collected papers from scientific and technical conferences, symposia, seminars, or other meetings sponsored or co-sponsored by NASA.

- SPECIAL PUBLICATION. Scientific, technical, or historical information from NASA programs, projects, and missions, often concerned with subjects having substantial public interest.

- TECHNICAL TRANSLATION. Englishlanguage translations of foreign scientific and technical material pertinent to NASA's mission.

Specialized services that complement the STI Program Office's diverse offerings include creating custom thesauri, building customized databases, organizing and publishing research results ... even providing videos.

For more information about the NASA STI Program Office, see the following:

- Access the NASA STI Program Home Page at http://Www.sti.nasa.gov

- E-mail your question via the Internet to help@sti.nasa.gov

- Fax your question to the NASA STI Help Desk at (301) 621-0134

- $\quad$ Phone the NASA STI Help Desk at (301) 621-0390

- Write to: NASA STI Help Desk NASA Center for AeroSpace Information 7121 Standard Drive Hanover, MD 21076-1320 
NASA/TM-1999-209143

ARL-TR-1976
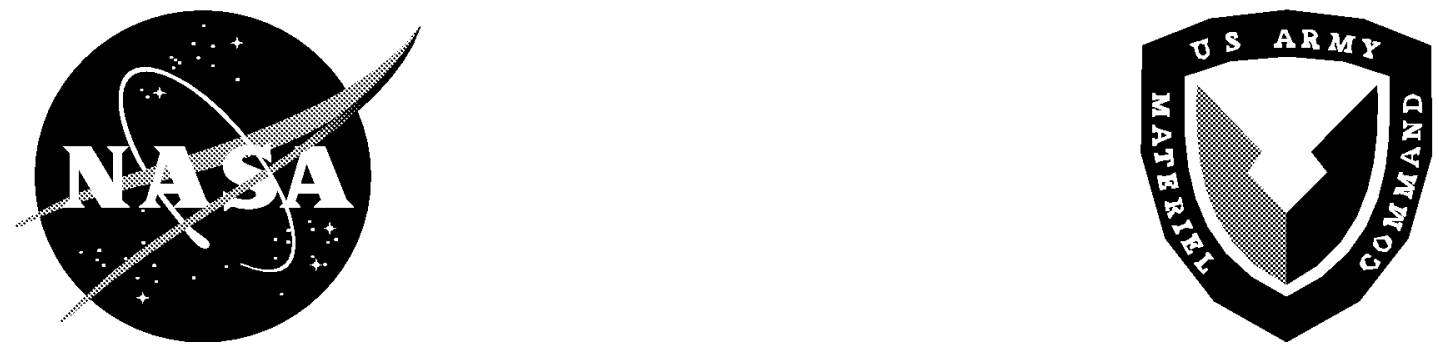

\section{An Overview of Landing Gear Dynamics}

Jocelyn I. Pritchard

U.S. Army Research Laboratory

Vehicle Technology Directorate

Langley Research Center, Hampton, Virginia

National Aeronautics and

Space Administration

Langley Research Center

Hampton, Virginia 23681-2199 
The use of trademarks or names of manufacturers in the report is for accurate reporting and does not constitute an official endorsement, either expressed or implied, of such products or manufacturers by the National Aeronautics and Space Administration or the U.S. Army.

Available from:

NASA Center for AeroSpace Information (CASI)

7121 Standard Drive

Hanover, MD 21076-1320

(301) 621-0390
National Technical Information Service (NTIS)

5285 Port Royal Road

Springfield, VA 22161-2171

(703) 605-6000 


\title{
An Overview Of Landing Gear Dynamics
}

by

\author{
Jocelyn Pritchard
}

\begin{abstract}
One of the problems facing the aircraft community is landing gear dynamics, especially shimmy and brake-induced vibration. Although neither shimmy nor brake-induced vibrations are usually catastrophic, they can lead to accidents due to excessive wear and shortened life of gear parts and contribute to pilot and passenger discomfort. Recently, NASA has initiated an effort to increase the safety of air travel by reducing the number of accidents by a factor of five in ten years. This safety initiative has spurred an increased interest in improving landing gear design to minimize shimmy and brake-induced vibration that are still largely misunderstood phenomena. In order to increase the understanding of these problems, a literature survey was performed. The major focus of the paper is to summarize work documented from the last ten years to highlight the latest efforts in solving these vibration problems. Older publications are included to understand the longevity of the problem and the findings from earlier researchers. The literature survey revealed a variety of analyses, testing, modeling, and simulation of aircraft landing gear. Experimental validation and characterization of shimmy and brake-induced vibration of aircraft landing gear are also reported. This paper presents an overview of the problem documented in the references together with a history of landing gear dynamic problems and solutions. Based on the assessment of this survey, recommendations of the most critically needed enhancements to the state of the art are given.
\end{abstract}

\section{Problem Definition}

Landing gear vibration includes self-induced oscillations referred to as shimmy and brake-induced vibration. Shimmy may be caused by a number of conditions such as low torsional stiffness, excessive freeplay in the gear, wheel imbalance, or worn parts. Brake-induced vibration includes conditions known as gear walk, squeal and chatter which are caused by the characteristics of friction between the brake rotating and nonrotating parts. Squeal refers to the high frequency rotational oscillation of the brake stator assembly whereas chatter and gear walk refer to the low frequency fore and aft motion of the gear.

\section{Shimmy}

\section{History and Background}

It is generally acknowledged that the fundamental contributions to understanding shimmy were made by the French whereas the Germans were responsible for much of the subsequent systematic development. In France and Germany shimmy was regarded as a problem that should be dealt with early in the design stages. In the United States, the general tendency was to fix a problem after it had occurred. The U.S. literature is quite extensive but was not considered to be representative of a systematic development. There were also significant contributions from other countries, including Russia whose papers did not begin to appear in the literature until the 1930's. (Ref.1)

The first fundamental contributions toward understanding the shimmy phenomenon emerged from the automobile industry in France around 1920. Of particular significance was that given by Broulhiet 
published in 1925. (Ref. 2) His observations on the role of tire mechanics on shimmy behavior are still followed today. While Broulhiet concentrated his attention on the tire, Sensaud de Lavaud (Ref.3) formulated the first fundamental shimmy theory. His theory incorporated a rigid tire that disregarded any effect of ground forces on the tire. Fromm (Ref. 4) also studied wheel shimmy in automobiles and recognized the similarities between the wheel vibration problems in automobiles and aircraft. He was one of the first to identify the vertical elasticity of the tire as the main contribution to the vertical displacement of the vehicle. His earlier investigations on rolling slip of deformable wheels led him to study the effect of sideslip or yaw of the rolling wheel due to lateral forces. Fromm's studies of lateral forces acting on the wheels led to the realization that these forces were coupled with the shimmy oscillation through the moment of the forces about the longitudinal axis. Either damping or build-up of the initial disturbance would occur depending upon the phase shift between the coupled motions. Von Schlippe and Dietrich (Ref. 5) made significant progress in defining the yaw angle and the swivel angle as arbitrary functions of time. Their tire concept was simplified as a thin band with lateral elasticity leading to simple expressions for the forces and moments. This eventually became known as the String Theory.

Some of the earliest investigations of shimmy problems in aircraft took place at Wright Field in Dayton, Ohio. In 1944 (Ref. 6) initial taxi testing of a fighter aircraft (Me 309) exhibited severe shimmy of the nose gear. Design of new piston shimmy dampers in coordination with landing gear manufacturers eliminated shimmy entirely for this aircraft. Other efforts at Wright Field (Ref. 7) included analysis development and validation by test. One such effort utilized a steel drum to perform studies on various airplane tires to correlate lateral deformation and lateral tractive force to banking angle and lateral-load force. In 1950, even though the shimmy problem had been studied for many years it was still a very common occurrence in automobiles, trailers, and aircraft. Physical control of shimmy was available in hardware such as shimmy dampers, but little was known about the cause of shimmy. Wright Air Development Center (WADC) started a program in 1951 to study the problem of shimmy and to learn the deficiencies of earlier efforts to combat the problem. The program included the development of a theory of shimmy, computer studies, experimental research on a laboratory model, and full scale testing. Even though earlier efforts traced the shimmy problem to the mechanical properties of the pneumatic tire, it was during this study that Moreland (Ref. 8) theorized that the tire support flexibility was a more important consideration than the tire mechanics. He contended that a shimmy theory based on the elastic properties of the tire alone was insufficient and that torsional and lateral rigidities, the wheel moment of inertia, and the weight of the strut were also critical in defining system stability. (Ref. 9) Only a fairly complete model of the structure including the tire properties could properly evaluate the stability of the system.

During the 1970's many investigators attributed landing gear vibration to wheel and tire imperfections and road surface roughness. References 10 and 11 found that when the frequency of the normal load oscillation was approximately twice the shimmy frequency, a decrease in the shimmy stability would occur. This loss of stability was primarily due to the variations of tire parameters with normal load. Other investigations found that shimmy motion was large when the frequency of wheel shimmy was close to the frequency of the wheel rotation. This resonance occurred at a particular forward velocity that was a function of the trail of the system. Studies concluded that braking forces tended to increase stability and that traction forces decreased stability even though these effects are small. By 1980 gear designs were having to adapt to increasing gross weight of the aircraft, increasing aircraft flexibility, higher ground roll speeds, and substandard landing fields. By now it was apparent that in order to fully understand the shimmy problem it was necessary to account for airframe flexibility and the coupling between the gear and airframe, and to weigh the effects of free play in gear components and damping devices on the system. There were many new areas of landing gear design that had emerged and needed attention. For example, ground simulators were being developed for pilot evaluation of steering capabilities that created a need for 
accurate mathematical models and flight testing for simulator verification. Structural and system testing were performed both during and after the design stage to substantiate the strength and performance of the gear. Tire braking and cornering data were practically non-existent during this time and oversimplification of many system parameters made for inaccurate models. Shimmy damping requirements often conflicted with good high-speed directional control. Composite carbon brakes were introduced and anti-skid systems were being used to optimize the braking performance and prevent skids and tire blowouts. Air-over-oil shock struts typically provided shock absorption where the damping was a function of the shock strut stroke. (Ref. 12)

\section{Airframe Flexibility Effects}

In references 8 and 9 Moreland characterizes shimmy by defining the relationship between a single non-dimensional quantity called the inertia ratio and the dynamics of the airframe. In most cases he studied, when the simplest systems were stable, the higher order systems were not less stable. To precisely describe the system and the shimmy phenomena, the mathematical model required 5 degrees of freedom: tire deflection, swivel angle, strut deflection, damper-linkage strain, and airframe motion. Comparisons of various systems were made with and without tire elasticity. The stability of the gear was influenced by 15 system parameters that were brought together in the shimmy analysis by a seventh order characteristic equation of the model. Routh's stability criterion was applied to the equation to study the effects of changing gear parameters on the stability of the gear. Plots of dimensionless quantities such as velocity ratio, damping ratio, mass ratio, trail ratio, and inertia ratio defined the stability boundaries.

In 1960 at NASA Langley Research Center a simple experimental model of an aircraft was used to study the effects of gear and airframe variables on nose landing gear shimmy behavior. (Ref. 13) A dynamically scaled skeleton model of an aircraft with a single main skid and castering wheel was towed on a moving belt runway at constant speed. The simplicity and size of the model made it relatively easy to vary model parameters for different configurations. This enabled evaluation of the gear through repeated observations of the model's response to varying conditions. Nose wheel steering and forms of shimmy damping were shown to have a stabilizing effect when the wheel was at an angle to the direction of motion. Another study of the role of airframe dynamics in shimmy analysis is described in reference 14. This report describes the theoretical and experimental study of the F-101 and F-104 nose landing gear shimmy. The dynamic response characteristics of the airplane fuselage were simulated during these tests with a mechanical fixture attached to an overhead platform that served as a mounting structure for landing gear. Frequency response characteristics were obtained experimentally by applying a periodic input to the fuselage at the nose gear station and recording the resultant bending and torsional motions. A graphical technique was used to fit the theoretical frequency response data to the experimental data to determine the parameters of the simulator from the transfer functions. Fuselage simulators were then designed and used to test the F-101 and F-104 aircraft systems.

Reference 15 presents an analytical method to determine the random vibration response of a flexible aircraft caused by runway irregularities transmitted through the main gear struts. The runway profile is represented as a stationary Gaussian random process. The statistical or power spectral approach yields only an average or root mean square value of the response. This method is useful for estimating fatigue effects in airframes and landing gear and has value for investigating the effect of parameter variations in the average sense. The major drawback of this approach is that in order for the probability distribution to be independent of the position along the length of the runway, the profile has to have the same degree of roughness at all points which is usually not the case. In 1976 a simplified model of the longitudinal vibration of a landing gear strut during landing and spin-up of the wheel was developed. The influence of 
the lateral forces on the rotating wheels during landing was studied while accounting for the interface between the strut and airframe. (Ref. 16) The elastic forces produced in the strut were calculated from landing gear and aircraft fuselage modes.

There have been recent efforts to approach the landing gear shimmy problem as a "flexible landing gear interaction with flexible aircraft" problem as in reference 17. This paper presents their approach to integrating the flexible properties of the aircraft into the shimmy investigation of nose landing gear during the development phase of a fighter aircraft. Taxi tests of the prototype indicated a severe shimmy oscillation at a frequency of $25.7 \mathrm{~Hz}$. After considering several potential fixes, it was found that increasing the pressure level in the nose gear tire removed the oscillation. Higher order models of landing gear legs were used to include all the features that are needed to represent the interactions with other subsystems during ground roll and landing simulations. The most important parameters in this shimmy investigation were the relaxation length or length of the ground contact area of the tire and the damping (friction) of the piston against the cylinder. The elastic fuselage modes were not considered to be important if the leg mode frequencies were well separated from the aircraft mode frequencies.

\section{Role of Tire Theories}

As previously mentioned, tire mechanics are intimately related to the shimmy problem. Tire models were very difficult to define due to the influence of the ground forces on tire behavior. Since the problem of shimmy and self-excited vibration of landing gear has existed for such a long time, many theories on the elastic deformation of tires had been proposed. There was much controversy over the advantages and disadvantages of these theories due to erroneous conclusions presented in previous papers on tire mechanics and shimmy. (Ref. 18) The tire theories were categorized into two basic groups. (Ref. 19) The major difference between the two groups is the number of coordinates used to describe the tire deformation. The first group yielded the simplest theory because there was no tangible model. The tire was taken into account by considering its kinematical behavior in the overall system. This group includes Moreland's point contact theory that assumed the interaction between the ground and the tire could be treated as a single point. (Ref. 8) This theory accounts for the effect of side force on the yaw angle of the tire and a time delay between the application of the side force and the steady state yaw. (Ref. 18) The second group utilizes a physical model of the tire. The most renowned example of this group is the string model. (Ref. 5) In this theory, the tire is approximated by an elastic string stretched around the outer edge of the wheel and attached by elastic springs. The elastic restoring effect of the tire is based on a linear principle that the deviation from the original swivel angle is proportional to the lateral deflection of the tire. The tire force and moment are found by integrating the infinitesimal effects of the deformations. (Ref. 18) This theory assumes pure rolling of the tire. Pacejka (Ref. 20) improved this approximation by using multiple stretched strings to simulate the width of the tire and nonstationary properties of the rolling tire are included. Most theories are linear which meant only small perturbations and no sliding in the contact area of the tire are addressed. These methods are considered to be effective for low frequency applications. Pacejka's method is particularly applicable to vibration problems of steering and suspension systems of vehicles at high speed and frequency. Simple equations are derived that relate inertial forces to dynamic displacements and external ground forces to static displacements of the tire center plane. His analytical results compared well with experimental data.

In 1957 Smiley (Ref. 21) developed a summary theory that combined many features of the existing theories and included comparisons with experimental data. The summary theory is a minor modification of the basic theory of Von Schlippe and Dietrich (Ref. 5) that includes tilting of the tire in more detail while omitting Pacejka's refinements necessary for wide tires. The kinematic relations of the lateral deflection of 
the tire ground-contact center point with the corresponding wheel coordinates of lateral deflection, swivel angle, and tilt angle are given for a rolling tire. Information about tire distortion is utilized in the derivation of these kinematic relations. Equations for the forces and moments on the wheel together with the kinematic relations establish the equations of motion for a rolling wheel. The theory was not validated for full-scale conditions and there was no reliable method at that time to predict the elastic characteristics of tires that were needed for shimmy analysis. Discrepancies were contributed to tire hysteresis effects and other nonlinear influences however, there were no strong indicators that nonlinear theory was necessary to predict stability boundaries. References 18 and 19 provide comparisons of the two basic theories from a validation standpoint as well as from computational and clarity aspects. It was found that both of these fundamental linear theories predicted shimmy characteristics of landing gear systems if the input parameters were properly chosen.

\section{Brake-induced Vibration}

Technological advances in aircraft led to smaller brakes with more energy to dissipate, lighter shock struts with higher strength materials, and increased flexibility all of which increased the likelihood of vibrations of landing gear due to braking action. Brake-induced vibrations in landing gear may be induced for several reasons. The self-excitation of modes due to negative damping arises from variations in the coefficient of friction with instantaneous slip velocity. Forced oscillations are due to irregularities in the friction surfaces. Self-excited whirl vibration is caused by eccentricity of rotating and non-rotating brake parts. The Information Report on brake dynamics of the SAE Committee A5 in 1997 (Ref. 22) categorized these landing gear dynamic vibration problems. A uniform method of classifying brake characteristics was given in terms of coefficient of friction, dynamic variation of friction coefficient, wear variation, and torque versus pressure characteristics. Self-excitation may be induced by large variations in the stiffness of brake components, poorly phased feedback in the anti-skid system, and tire lock-up corresponding to maximum drag. Solutions to these vibration problems included provision of basic aircraft parametric data from airframe manufacturers for analysis and testing. Data collection from flight testing is needed for skid control on wet and dry surfaces at shimmy speeds. Brake history and frequency and amplitude of vibration are desirable in order to characterize a pattern.

One of the early investigations on brake vibration was reported in reference 23 where a study of landing gear vibration due to brake chatter and squeal during taxi and landing was performed. The report contains both experimental (static, dynamic, and taxi tests) and theoretical studies explaining the basic phenomena and pointing out the important design considerations. Static tests were conducted to determine parameters such as weight and mass moments of inertia, damping ratios, and spring rates that were needed for analytical studies. Dynamic tests included brake and strut dynamometer testing that measured drag loads, brake pressure, wheel speed, side force, fore and aft motion of the axle, and angular acceleration of the axle. Taxi tests involved a number of relatively uncontrollable variables which is why it is difficult to achieve the same results with the dynamometer tests. Systems of individual masses, springs, and dampers were used to represent the landing gear to aid in studying the effects of friction characteristics of the brake on the dynamic stability of the gear. Only linear solutions were considered in this report, however, it was recommended that non-linear friction characteristics be included in future theoretical studies. The dynamometer tests revealed a connection between the chatter frequencies and the wheel rotation. Theoretically, decreases in chatter amplitudes were noticed for increases in strut damping, rolling radius, and total mass. Another effort to study landing gear chatter and brake squeal vibrations was at the Naval Research Laboratory during the development of a digital program to simulate the DC-9 aircraft main gear slowing to a stop. (Ref. 24) The analytical model represented the fore and aft motion of the gear with 
accompanying rotational motion at the gear axle. Comparison of computed responses and measured data indicated reasonable simulation accuracy. The analysis showed that brake torque was the primary contributor to chatter and squeal vibration. Increasing the brake torque in combination with diminishing brake rotor to stator angular velocity instigated the vibration. This function effectively produced a negative damping that sustained or increased the vibration amplitudes. Attenuation methods included using a mix in the brake lining that ensured a flat brake torque function. Vibration absorbers were also suggested even though an excessive weight penalty existed for chatter vibration absorbers.

At Wright Patterson AFB dynamometer tests were performed to simulate normal service conditions experienced by the brake on the T-38A aircraft for the purpose of investigating the brake characteristics (Ref. 25). Brake torque, hydraulic pressure, dynamometer flywheel speed, and test wheel speed were measured during dynamometer tests performed on a B. F. Goodrich 2-727 brake assembly at three different deceleration and brake initiation speeds to determine the kinetic friction and relative rubbing velocities. The experimental data and the analysis both indicated that the system was stable. Dynamometer test temperatures were used to investigate the temperature response of the brake rotor and stator during braking. A comparison to the analytical model showed good reliability for predicting rubbing surface temperatures. Predicting these temperatures accurately is advantageous to designers due to the potential for strut chatter and metallurgical design criteria. All tests were conducted on new brakes, however, it was suggested that these tests and analyses should also be performed on worn brakes to observe any differences in the results. More recent investigations emphasized the effect of the variation of friction coefficient with slip velocity between rotors and stators as in reference 26 . This report also gives an overview of the stability and modal interactions caused by nonlinear negative damping at the brake friction interface. It was emphasized in reference 27 that the braking system should be analyzed as a global system rather than as separate components due to the coupling between the parts. Nonlinear modeling of aircraft landing gear brake whirl and squeal was discussed in references 28-30. These studies found that system stability could be altered by changes in the brake friction coefficient, pressure, stiffness, geometry, and various brake design parameters.

\section{Modeling and Simulation}

Traditionally the emphasis in analytical prediction capability was on landing impact loads since these were considered to be the largest that the aircraft would experience. The oscillatory loads from taxiing were deemed as secondary. The emphasis eventually included the requirement to more accurately model the gear to improve the dynamic response predictions. The state-of-the-art in modeling techniques for landing gear prior to 1980 was summarized in reference 31. There was a need for experimental verification of the details of the gas compression process and determination of the parameters that affect this process such as hydraulic fluid compressibility, fluid-gas mixing, and deformation of the gear chamber. The orifice coefficients were considered extremely important for calculating the response of the gear and very accurate procedures were needed to determine these values for hydraulic damping. Since the orifice flow is highly unsteady, problems arose when steady flow hydraulic force models were used in taxi simulations. Most models included friction as dry or Coulomb friction but frictional forces were sometimes left out of the analysis because a good method for measuring these forces was not known. Normal forces on the bearings that create friction forces were dependent on the gear geometry and the wheel loading. For flexible models where the deformation of the gear was included in the analysis, determination of the normal forces became very complex. The tire was modeled as a simple spring (linear and nonlinear) with point contact with the ground and linear viscous damping. Tire stiffness was represented by static load deflection curves either provided from experiment or manufacturer. The tire interface with the ground and the geometry of the tire footprint was an area that needed more attention. Numerical simulations could be used 
with some confidence to predict fatigue and peak loads if the analysis had been evaluated with taxi or drop test data. Modeling and simulation efforts over the past ten years have become fairly sophisticated as input data has been carefully scrutinized and experiments are conducted to validate models. Efforts to model nonlinearities such as damping and friction characteristics were becoming more prevalent. Several examples of modeling gear systems are given below.

In reference 32 an analysis of fatigue of light aircraft landing gear using random properties and surface profiles was developed. The system was modeled as a linear, 1 DOF nonstationary vibrating system referred to as a random parametric vibration problem that uses a recently developed random matrix method. Reference 33 is a follow up to the work described in reference 3 with nonstationary damping and random nonstationary loads included. The random matrix method was shown to be better suited for this type of problem than a hybrid Monte Carlo technique. In reference 34 modeling and parameter identification of single degree of freedom structural systems are investigated. Experiments were conducted to measure the free response of these structural systems and the measurements were used to formulate system models and parameters. Models include a linear, damped oscillator and a nonlinear shock strut with and without friction forces. Results showed that it is possible to model and identify a physical structure such as a damped oscillator with damping effects. Comparisons between the response predicted by the model and the response measured experimentally agreed for the first few seconds of motion but then deteriorated in later stages. This was due in part to ill-conditioning of the equations even though experimental measurements were used to identify the model parameters of the system. Models developed in references 35-39 include the effects of linkage dynamics, damper mounting characteristics, Coulomb friction, nonlinear tire, air spring, oleo damping forces, torsional freeplay, and spring hardening effects of bending and torsional stiffness.

An example of non-linear modeling involved an A-6 Intruder nose gear. The model included nonlinear effects in the pneumatic air spring, stick-slip friction, velocity squared damping, geometry governed discharge coefficients, and tire model. Analytical results were in excellent agreement with test data that was acquired at NASA Langley Research Center. (Ref. 40) Reference 41 describes linear and nonlinear analysis methods applied to investigate the shimmy of a simple nose gear model. The nonlinear shimmy model consisted of torsional dynamics of the gear, the forces, moments, and lateral elasticity of the tire using elastic string theory. Results showed that the occurrence of shimmy increases with increasing velocity, lower torsional damping, and increasing vertical force. The numerical simulation results confirm the stability of the linear system and provided additional information concerning the nonlinear regions. Reference 42 is an example of a model that includes an error feedback control law for anti-skid braking simulation used in determining the effects of structural parameters on gear walk instability. The effect of longitudinal stiffness of the tire, the vertical damping of the tire, and the inclination angle of the strut on gear walk stability were investigated.

There were also efforts to study and compare modeling techniques. Reference 43 developed simulations and analyses of conventional oleo-pneumatic landing gear during taxi and landing impact. Simplification of the model and the effect of certain element omissions on the model fidelity were pointed out. For example, constant spring and damping coefficients will not provide a realistic simulation effect. The hydraulic force is a function of metering pin and strut closure and therefore cannot be represented by a single force closure rate. This curve is different for acceleration and deceleration phases. Reference 44 gives a review of two landing gear shimmy models demonstrating the use of the Moreland tire model and the Von Schlippe-Dietrich tire model. The models were used to perform a parametric study of the effect of numerical variation of several input parameters on the stability of the gear. A comparison is made of the analytical results to experimental data showing good agreement of the limit cycle oscillation frequency. Both analyses were considered to be successful in determining the stability characteristics of landing gear. 
The results suggested that dynamic modeling of the gear would significantly improve the accuracy of the analytical predictions. It was discovered that the spring stiffness values were stability critical parameters and if the fuselage flexibility effects are not taken into account, the measured values of the stiffness parameters may be in error by as much as 3 times the actual values.

General-purpose computer programs were also being developed to model complete landing gear systems. An example of this type of modeling is described in reference 45 where the Dynamic Analysis and Design System (DADS) program is used to model the response of two types of landing gear on damaged and repaired runways during landing, taxiing, and take off. Both the cantilevered and the articulated models included nonlinear effects such as the hydraulic orifice damping, pneumatic air spring, bearing friction forces in the strut, and a tire-load deflection curve. These models could be used as stand alone gear on a runway surface or combined together to simulate an entire aircraft. The dynamic analysis and simulation show results such as strut loads and stroke for different runway profiles. The plots indicate stick motion of the strut and the animation capability in DADS gives an advantageous view of the response of the gear rolling over a runway.

\section{Finite Element Modeling}

Finite element modeling has become a useful tool for studying dynamic stability issues of landing gear. Reference 27 describes finite element modeling of the whirl and squeal modes of landing gear and braking systems. Correlation between the analysis and various system component tests as well as the performance of the complete model and actual system during operation are performed. Models include landing gear, wheels, brakes, and tires. Design sensitivity studies are also used to evaluate component changes during the design process. A feasibility study of computing nonlinear finite element simulations of whirl and squeal dynamics is discussed in reference 28. DYNA3D is an explicit finite element code that uses the central difference method to integrate the equations of motion in time. The model includes the aircraft inertia and tire flexibility effects without adding extensive computational expense. Advantages of using this method over more commonly used linear complex finite element analysis are evident in the nonlinear transient analysis capability, the ability to model nonlinear stiffness and damping effects of hydraulic fluid, modeling whirl and squeal instabilities with negative damping, and provision for modeling a sliding interface.

\section{Software Development}

Reference 46 uses a library of components based on finite element methods which range from beams and springs to very specific landing gear elements such as shock absorbers, actuators, flexible sliders, and flexible wheel elements. Customization of elements is also available through user defined elements. Results presented include simulation of a drop test, taxiing on repaired runway, tire burst during rollout, and shimmy of a two-wheeled cantilever gear. Reference 47 developed a very comprehensive landing gear model and simulation software capability that integrates landing gear and braking systems with an aircraft for the purpose of parametric design. The software can be used during the conceptual design stage or to evaluate proposed modifications for an existing configuration. All phases of aircraft landing gear dynamics have been included to a fairly high level of detail including take-off, landing, steering, and taxiing. Also flexibility of the strut and bogie were modeled. The software is composed of modules that correspond to different subsystems or components such that a wide range of configurations can be modeled from a single landing gear strut to a whole aircraft with multiple gear. The software has the capability of modeling the aircraft as a flexible body that may be important in configurations that have more than two 
main gear across the fuselage. A finite element model is used for the strut component of the gear. Since the frequencies and mode shapes change as the gear is extended or compressed the model is evaluated at several different positions and interpolated in between. A modal reduction routine is used for removing unwanted modes in order to preserve the efficiency of the software. The oleo, bogie, brakes and wheels, braking servo, steering actuation, control systems, tires, and runway profile are also included in the model. The software has been validated with test data and an example of a drop test is given in the paper.

\section{Sensitivity Analysis and System Studies}

With the development of more accurate models for analyzing gear vibration problems, system sensitivity studies became feasible and valuable in the design and evaluation of landing gear dynamics. Ref 14 describes a sensitivity study of several service variables on the dynamic stability of the F-101 and F-104 landing gear systems. Among the studies are the effects of wear, manufacturing tolerances, and normal maintenance procedures on the nominal gear. These studies were helpful in determining if optimum performance of the gear could be achieved by changing the values of the nominal service variables. Also, it was important to establish guidelines that stated if any deviations in these service variables from their nominal values would be detrimental to the performance of the aircraft. Torsional free play of the F-104 gear was found to have the most profound effect on the stability of the gear, particularly for fully extended operation. Tire unbalance reduced the dynamic stability of the gear when adverse values of other service variables were present such as air in the steer-damp unit or excessive torsional free play. For the F-101 gear, tire unbalance was shown to have a severe effect on the stability. Reference 48 describes an analytical method of determining the sensitivity of various parameters of the landing gear and the braking system on the landing gear dynamics during landing. The differential equations of motion of an 11 degree of freedom system in generalized coordinates are written using Lagrange equations which are solved with variations of the parameters. During the design modifications of the F-15 reported in reference 49, landing gear shimmy tests were performed using a dynamometer facility and prototype landing gear. Several instances of shimmy were encountered during testing and the results indicated that shimmy speed was a function of strut torsional free play. Nonlinear analyses showed the sensitivity of shimmy speed to changes in tire parameter values and frictional coefficients. The sensitivity analysis reported in reference 50 showed that forward speed, vertical velocity, pitch attitude, and damping coefficients of the landing gear have the largest effect on the g loads at touchdown. The nonlinear model described in reference 37 varied system parameters to study the dynamic behavior of a dual wheel nose-gear system. The study included parameters such as wheel span and cant angle, mass of the torque arms and its relative position to the shock strut, torque arm stiffness, damper stiffness, wheel size and mass, and tire vertical and lateral stiffness.

Messier-Dowty has studied shimmy phenomena in order to improve the prediction of the dynamic behavior of landing gear systems. In reference 51 they have developed several models with many input parameters, particularly non-linear parameters and made comparisons to test data. Simulations show sensitivities of shimmy stability to variations in these parameters and reinforce the need for taking nonlinearities into account. The effects of longitudinal tire stiffness, vertical damping, and inclination angle of the strut on gear walk stability are investigated in reference 42 . The analytical model was developed to study the behavior of main landing gear during taxi and braking. The model includes an error feedback control law for anti-skid braking simulation. In Reference 52 system studies were performed for landing impact and taxi for three types of dual-chamber shock struts to aid in the selection process when designing landing gear for different applications. The strut behavior was calculated for the design energy conditions of a transport aircraft. No validation of the equations and results was performed. Reference 53 gives an example of a shock strut model for an articulated landing gear that was used for the purpose of 
comparing different linkage system configurations. Linkage mechanisms are important for achieving mechanical advantages and other improvements in weight, reduced friction, and steering. The strut model included hydraulic damping and pneumatic spring forces, but seal and bearing friction were neglected during landing conditions. The tire model was relatively simple having empirical coefficients obtained from static testing. The simulation also included aerodynamics, engine model, and ground effects. Reference 54 developed a numerical to study the advantages and disadvantages of decreasing the initial charge pressure of the air-oil chamber in the strut. The analysis was performed with and without the effects of the relaxation properties of the tire which influences the maximum load point in the lower part of the strut but does not affect the upper part of strut or fuselage. The advantage of shortening the strut did not outweigh the disadvantage of increasing the stiffness of the strut both caused by "soft-filling".

\section{Testing and Validation}

The literature was reviewed for examples of testing for verification of analytical models, accurate parameter identification for input into analytical models, and determining the stability of gear designs. Reference 55 describes analytical and experimental studies of shimmy for the DASH 7 and DASH 8 aircraft to understand nose gear shimmy and to aid in the development of analysis methods for predicting shimmy. Shimmy occurred during service of the DASH 7 nose gear and was predicted during the design of the DASH 8 main gear. Aircraft ground testing of a DASH 7 nose gear investigated variables such as free-play in the scissors, effects of spin-up transient oscillations, and time-delay steering mechanism. The analysis model used represents backlash, bearing friction, scissors stiffness and free play, and fuselage torsional stiffness and free play. The frequencies predicted were $20 \%$ higher than the values measured and was attributed to mass and stiffness modeling inaccuracies. Effects of free play and mass balance on stability were investigated. The main landing gear of the DASH 8 was prone to shimmy due to its long flexible design. Analytical results showed that increasing torsional stiffness and side bending stiffness of the gear would increase stability. Mechanical trail was increased to the maximum to improve stability also. The DASH 7 nose landing gear shimmy problem was contained at the expense of increased maintenance cost, pilot workload, and in some cases airplane weight. In the case of the DASH 8, all 400 airplanes in service are shimmy free but at the expense of increased time and effort to establish the final design with a weight penalty.

There are different approaches to testing landing gear. Test results may therefore differ as discussed in reference 56. Large differences still exist between dynamometer and airplane test results. Although it is possible to predict the dynamometer results with an analytical model of the dynamometer test setup if the dynamics of the overhead rig are included, the dynamometer predicts much more stable behavior than the actual landing gear on the aircraft. The lack of complete simulation of the torsional squeal modes interaction with the rest of the landing gear structure, and the lack of simulation of low frequency modes can result in significant differences between the stability of important modes in the lab as compared to the actual aircraft. Another large difference between the dynamometer and the aircraft landing gear is the modal density in the low frequency range between 0 and $50 \mathrm{~Hz}$. For the example discussed in the reference the main landing gear had fifteen modes in this range where the simulator of the gear had only two. The lack of simulation of the low frequency modes of the landing gear system can result in significant differences between the stability of important modes in the laboratory as compared to the aircraft. The author states that a simulator of this type can be used to predict airplane performance only if it is used in conjunction with a detailed analytical model of the complete landing gear system. Reference 57 gives a brief overview of a 1993 NASA test program to study aircraft nose gear shimmy. The parameters were torsional stiffness, torsional freeplay, wheel balancing, and worn parts. Steerable nose wheels were 
particularly susceptible to shimmy problems. Test results of the Shuttle nose landing gear compared with that of a steel dynamometer showed little difference except in the case of a simulated flat tire test. This test was shown to be significant only in the dynamometer data. Basically vertical load had little effect on maximum steering collar rotation, maximum axle acceleration and maximum wheel swivel acceleration for the shuttle nose gear tests which also confirmed earlier dynamometer data that shimmy did not appear to be a problem. Reference 58 describes methodology to measure nose landing gear shimmy parameters using T46 static test article and static force-deflection measurements. The shimmy stiffness and torsional freeplay parameters were then input into a shimmy analysis that incorporated the Moreland tire model. Stability was predicted over a speed range of 20 to 140 knots. The prediction was validated through taxi tests of the T46. In reference 59 a mathematical model was developed to analyze the stability of the F-28 and other similar gear and then validated through ground vibration tests and aircraft taxi tests. It was found that this gear was basically unstable. An examination of the modes of the gear model found that the torsional-yaw mode had negative damping for velocities above $70 \mathrm{~m} / \mathrm{s}$ at a $.25 \mathrm{~m}$ vertical deflection of the shock absorber. A shimmy damper was included at the apex of the torque links that proved to be stabilizing in the analysis as well as subsequent flight tests. Eventually experimental testing in landing gear systems and components was performed to determine critical input parameters for improving analytical methods. Taxi tests of the airplane were not conducive to developmental work on the gear or for broad investigations of the effects of system parameters, therefore laboratory tests were the most cost-effective way to investigate the stability of the gear.

Stability characteristics have been examined in the laboratory over the complete range of speed, vertical load, and service parameter changes. Reference 60 examines several major differences between laboratory tests and airplane tests. The mounting structure to which the landing gear is attached affects the frequency and damping. The curvature of the flywheel surface affects the rolling dynamics of the tire such as cornering power, relaxation length, and tire lateral spring rate. The melted rubber on the flywheel surface will change the friction between the tire and the flywheel surface causing the gear to be more stable than the actual. Landing gear exhibit non-linear characteristics such as friction and damping that are dependent on the level of excitation. Lab testing usually involves gear in new condition that is non-typical of actual landing gear systems. Because of these differences, the predictions are carried out by an experimentally verified analysis rather than directly from lab test results. Reference 60 describes one such effort to examine shimmy instability analytically during the design stages and by experimental testing. The critical input parameters for the analytical study were flexibility coefficients, damping and steering characteristics, fuselage frequency response, frictional torques, deadband values, and tire parameters which were determined in lab tests. Correlation between the lab tests and the analysis was very good. The complete landing gear was then tested either in laboratory simulation or taxi tests on the actual airplane.

\section{Assessment and Recommendations for Future Work}

Significant improvements in analytical predictions can be made if gear and tire parameters such as stiffness, damping, and friction are known as functions of load on the gear or aircraft ground speed. (Ref. 61) Obtaining these parameters can be very labor intensive. Some landing gear dynamicists are of the opinion that there is a need for standardized analytical modeling capabilities that are comprehensive and accurate but not cumbersome or computer intensive. These tools should be versatile enough to handle different types of gear as well as wheel/tire configurations and should be well maintained and documented. A database of predictions of aircraft contributions to the gear parameters would eliminate the need for labor intensive measurements on the aircraft. The need for a better understanding of damping and friction in the gear still exists today. Reference 62 gives an overview of the needs for improvements in analytical 
modeling and testing. They contend that simulation models can be used in parametric studies to improve shimmy stability of gear designs, however, a total assessment of the system stability requires analyzing the entire operating range of the aircraft and can be difficult to obtain in this manner. In the open literature they found few publications that dealt with model simulations having significant impact on landing gear design. Still simulation can provide a less expensive alternative to full scale testing. Test findings indicate that torsional freeplay tends to destabilize the system whereas friction forces have a stabilizing effect. Separation of lateral and torsional frequencies through lateral and torsional stiffness modifications, adding negative or large positive mechanical trail, mass balance applied to the wheel axle, steering systems, and shimmy dampers are all methods for improving shimmy stability according to the references cited. Worn parts, tire wear, and tire inflation also adversely affect shimmy stability.

Landing dynamics issues have been the focus of the Aircraft Landing Dynamics Facility (ALDF) at NASA Langley Research Center since its inception in 1956. Landing gear vibration could be studied further in this facility. In January 1998 a workshop was held at NASA Langley where the aircraft landing gear community was invited to discuss vibration problems. Landing gear and tire manufacturers, commercial airline and general aviation personnel, FAA, and WPAFB were in attendance. The overall consensus was that analytical tools were available to predict shimmy and brake-induced vibration, but there was a need for accurate tire characterization to provide input for the models. They requested an update to the NASA Technical Report R-64 cataloging mechanical properties of aircraft tires including dynamic properties of radial and advanced bias-ply tires. Since the data for the original R-64 document were acquired at the ALDF it seemed appropriate to perform the update activity there as well. The test plan and schedule has been initiated and testing is projected to start in the summer of 1999.

\section{Concluding Remarks}

In order to increase understanding of landing gear shimmy and brake-induced vibration problems, a literature survey on landing gear dynamics was performed. The major focus of the paper was to summarize work documented from the last ten years to highlight the latest efforts in solving these vibration problems. Older publications are included to understand the longevity of the problem and the findings from earlier researchers. The literature survey revealed a variety of analyses, testing, modeling, and simulation of aircraft landing gear. Experimental validation and characterization of shimmy and brake-induced vibration of aircraft landing gear were also reported. This paper presented an overview of the problem documented in the references together with a history of landing gear dynamic problems and solutions. Based on the assessment of this survey, recommendations of the most critically needed enhancements to the state of the art were given.

\section{References}

1. Dengler, M; Goland, M.; Herrman, G., "A Bibliographic Survey of Automobile Aircraft Wheel Shimmy", WADC-TR-52-141, December 1951.

2. Broulhiet, G., "The Suspension of the Automobile Steering Mechanism: Shimmy and Tramp", Bull Soc. Ing. Civ. Fr. 78, pp. 540-554, July 1925.

3. Sensaud de Lavaud, D. "Shimmy, Pseudo-Shimmy and Tramp of an Automobile", C.R. Acad. Sci., Paris, Fr. 185, pp. 254-257, July 1927.

4. Fromm, H., "Brief Report on the History of the Theory of Shimmy", NACA TM 1365, pp.181, 1954.

5. Schlippe, V.B. and Dietrich, R. "Shimmying of a Pneumatic Wheel”, NACA TM 1365, 1954. 
6. Maier, E. and Renz, M., "Tests On Shimmy with the Nose Landing Gear of the Me 309 and the FKFS Trailer", N-579 AAF, Air Material Command, Wright Field Technical Intelligence, Dayton, Ohio, 1947.

7. Dietz and Harling, "Examination of Lateral Stress and Shimmy Phenomena on Airplane Wheel Tires", 1156.2 48, Headquarters Air Material Command, Wright Field, Dayton, Ohio, Aug. 1950.

8. Moreland, W.J., "Landing Gear Vibration", AF Technical Report No. 6590, October 1951.

9. Moreland, W.J., "The Story of Shimmy", Journal of the Aeronautical Sciences, Vol. 21, No. 12, December 1954.

10. Ho, F.H. and Lai, J.L., "Parametric Shimmy of a Nosegear", Journal of Aircraft, Vol.7, pp. 373-375, 1970.

11. Podgorski, W.A.; Krauter, A.I.; and Rand, R.H., "The Wheel Shimmy Problem: Its Relationship to Wheel and Road Irregularities", Vehicle System Dynamics, Netherlands, pp. 9-41, March 1975.

12. Attri, N.S. and Amberg, R.L., "Advances in Landing Gear Systems", AGARD CP-299, pp. 13/1-20, 1981.

13. Faber, S. "Dynamic Model Investigation of a Landing-Gear Configuration Consisting of a Single Main Skid and a Nose Wheel", NASA TN D-213, February 1960.

14. Black, R.J., "An Experimental and Theoretical Study of the Effects of Service Variables on the Dynamic Stability of Airplane Nose Landing Gear Shimmy", Bendix Report No. SV-62-4 (870), Bendix Products Aerospace Division, The Bendix Corporation, November 1962.

15. Kirk, C.L., "Analysis of Taxiing Induced Vibrations in Aircraft by the Power Spectral Density Method", Technical Report AFFDL-TR-72-74, January 1973.

16. Maksimova, T.I., "Vibrations of the Principal Struts of a Landing Gear During Landing", Theory and Practice of Designing Passenger Aircraft, (A77-27126 11-01), pp.345-350, 1976.

17. Luber, W.; Kempf, G.; and Krauss, A., "Self-Induced Oscillations of Landing Gear as an Integral Landing Gear Aircraft System Problem", AGARD-R-800, March, 1996.

18. Collins, R. L., Theories on the Mechanics of Tires and Their Applications to Shimmy Analysis", Journal of Aircraft, Vol.8, No.4, April 1971.

19. Sperling, E., "Shimmy Problems of Landing Gears Caused By Elastic Deformation of Tires", Proceedings of The $15^{\text {th }}$ Congress of the International Council of the Aeronautical Sciences, London, U.K., September 7-12, 1986.

20. Pacejka, H.B., "Approximate Dynamic Shimmy Response of Pneumatic Tires", Vehicle System Dynamics 2, pp.49-60, 1973.

21. Smiley, R.F., "Correlation, Evaluation, and Extension of Lineraized Theories For Tire Motion and Wheel Shimmy", NACA Report 1299, 1957.

22. Society of Automotive Engineers Subcommittee A-5A, Wheel, Brakes, and Skid Controls, of SAE Committee A5, Aerospace Landing Gear Systems, "Brake Dynamics Information Report", SAE AIR 1064C, January 1997.

23. Edman, J.L., “Aircraft Vibrations Due To Brake Chatter and Squeal”, WADC Technical Report 55-326, Wright Air Development Center, Air Research and Development Command, USAF, Wright Patterson Air Force Base, OH, October 1955.

24. Biehl, F.A., "Aircraft Landing Gear Brake Squeal and Strut Chatter Investigation", The Shock and Vibration Bulletin, Naval Research Laboratory, Washington, D.C., January 1969.

25. Brewer, J.D., "Experimental Investigation of Brake Characteristics Conductive to Strut Chatter", Report \#: AD-780505 GAW/MC/74-2, Thesis for Master's Degree, Air Force Institute of Technology, Wright Patterson AFB, OH, March 1974. 
26. Black, R.J., "Self Excited Multi-Mode Vibrations of Aircraft Brakes With Nonlinear Negative Damping", Proceedings of The $15^{\text {th }}$ Biennial Conference on Mechanical Vibration and Noise, Boston, MA, September 17-20, 1995.

27. Chang, C.F., "Dynamic Finite Element Modeling of Aircraft Landing System", Proceedings of the ASME Design Engineering Technical Conference, Boston, MA, 1995.

28. Travis, M.H., "Nonlinear Transient Analysis of Aircraft Landing Gear Brake Whirl and Squeal", Proceedings of The $15^{\text {th }}$ Biennial Conference on Mechanical Vibration and Noise, Boston, MA, September 17-20, 1995.

29. Liu, S.Y.; Gordon, J.T.; and Ozbek, M.A., “A Nonlinear Model For Brake Squeal Analysis I - Model Description and Solution Methodology", AIAA Dynamics Specialists Conference, Salt Lake City, UT, April 18, 1996.

30. Liu, S.Y.; Gordon, J.T.; and Ozbek, M.A., “A Nonlinear Model For Brake Squeal Analysis II Stability Analysis and Parametric Studies", AIAA Dynamics Specialists Conference, Salt Lake City, UT, April 18, 1996.

31. Batill, Stephen M., "A Study of Analytic Modeling Techniques For Landing Gear Dynamics", AFWAL-TR-82-3027, May 1982

32. Huntington, D.E., and Lyrintzis, C.S., "Random Parametric Vibration in Aircraft Landing Gear", Proceedings of the $37^{\text {th }}$ AIAA/ASME/ASCE/AHS/ASC Structures, Structural Dynamics, and Materials Conference, Salt Lake City, UT, April 1996.

33. Huntington, D.E. and Lyrintzis, C.S., "Nonstationary Random Vibration in Light Aircraft Landing Gear", Journal of Aircraft, Vol. 35, No. 1, pp.145-151, February 1998.

34. Batill, S.M. and Bacarro, J.M., "Modeling and Identification of Nonlinear Dynamic Systems With Application to Aircraft Landing Gear", Proceedings of the $29^{\text {th }}$ AIAA/ASME/ASCE/AHS Structures, Structural Dynamics, and Materials Conference-Part 2, Williamsburg, VA, April 18-20, 1988.

35. Yadov, D. and Ramamoorthy, R. P., "Nonlinear Landing Gear Behavior at Touchdown", Journal of Dynamic Systems, Measurement, and Control, Vol. 113, pp. 677-683, December 1991.

36. Baumann, J.: Barker, C.R.: and Koval, L.R., "A Nonlinear Model For Landing Gear Shimmy", Proceedings of the ASME Winter Annual Meeting, Atlanta, GA, December 1-6, 1991.

37. Li, G.X., "Modeling and Analysis of a Dual-Wheel Nose Gear: Shimmy Instability and Impact Motions", Proceedings of the SAE Aerospace Atlantic Conference and Exposition, Dayton, Ohio, April 20-23, 1993.

38. Bespalov, V.A.; Metrikin, V.S.; and Peisel, M.A., "On the Dynamic Stiffness of a Landing Gear Nose Strut Hydraulic Damper System”, Izvestiya VUZ. Aviatsionnaya Tekhnika, Vol. 32, No. 3, pp. 3-6, 1989.

39. Feld, Dennis J., "Analytical Investigation of Damping of Landing Gear Shimmy", Proceedings of the Aerospace Technology Conference and Exposition, Long Beach, CA, Oct. 1-4, 1990.

40. Daniels, J.N., "A Method for Landing Gear Modeling and Simulation With Experimental Validation", NASA CR 201601, June 1996.

41. Somieski, G., "Shimmy Analysis of a Simple Aircraft Nose Landing Gear Model Using Different Mathematical Models", Aerospace Science and Technology, Vol.1, No. 8, pp.545-555, 1997.

42. Zhagn, L. "Numerical Analysis of the Stabilities on Main Landing Gear Walking", Proceedings of the Third Asian-Pacific Conference on Computational Mechanics, Seoul, Korea, September 16-18, 1996.

43. Kapadoukas, G. and Self, A., "The Simulation of Aircraft Landing Gear", Systems Analysis Modeling Simulation, Vol. 21, No. 4, pp. 237-245, 1995.

44. Krabacher, W.E., “A Review of Aircraft Landing Gear Dynamics”, AGARD-R-800, March, 1996. 
45. Lee, T.W., "Dynamic Response of Landing Gears on Rough Repaired Runway", Proceedings of The Aerospace Technology Conference and Exposition, Long Beach, CA, September 23-26, 1991.

46. Thomas, P.; Geradin, M.; and Guyot, B., "Dynamic Simulation of Landing Gears", International Forum on Aeroelasticity and Structural Dynamics, Strasbourg, France, pp.1077-1096, May 1993.

47. Cowling, D. and Shepherd, A., "The Prediction of Landing Gear Behavior Using Dynamic Simulation", Proceedings of the International Forum on Aeroelasticity and Structural Dynamics, Manchester Business School, U.K.,June 26-28, 1995.

48. Maksimova, T.I.; Priven, V.D.; and Tomin, B.P., Vibrations of Landing Struts During Braking", Theory and Practice of Designing Passenger Aircraft, (A77-27126 11-01), pp. 337-345, 1976.

49. Grossman, D.T., "F-15 Nose Landing Gear Shimmy, Taxi Test and Correlative Analyses", Proceedings of The Aerospace Congress and Exposition, Los Angeles Convention Center, CA, October 3-16, 1980.

50. Kothari, S.S.; Ananthasayanam, M.R.; and Rajaiah, K., "Analysis of Dynamical Behaviour of an Aircraft at Touchdown", Proceedings of the $31^{\text {st }}$ Aircraft Symposium, Hikoki Shinpojiumu Koenshu, Japan, Vol. 31, pp. 82-85, 1993.

51. Woerner, P. and Noel, O., "Influence of Nonlinearity on the Shimmy Behaviour of Landing Gear", AGARD-R-800, March, 1996.

52. Nie, H. and Qiao, X., "Dynamic Bahavior Analysis For Landing Gear With Different Types of DualChamber Shock Struts", Chinese Journal of Aeronautics, Vol. 4, May 1991.

53. Cameron, A.M.; Hogg, C.R.; and Harris, C.J., "Flight Simulation: Comparison of Articulated Gear Leg Models", Proceedings of The $27^{\text {th }}$ Summer Computer Simulation Conference, Ottowa, ON, Canada, July 24-26, 1995.

54. Zhu, D., “Some Dynamic Problems in Design of Aircraft Landing Gear", Proceedings of the $18^{\text {th }}$ Congress of the International Council of the Aeronautical Sciences, Beijing, China, September 20-25, 1992.

55. Glaser, J. and Hrycko, G., "Landing Gear Shimmy - De Havilland's Experience”, AGARD-R-800, March, 1996.

56. Black, R.J., "Realistic Evaluation of Airplane Brake Vibration By Laboratory Test and Analysis", Proceedings of The $15^{\text {th }}$ Biennial Conference on Mechanical Vibration and Noise, Boston, MA, September 17-20, 1995.

57. Yager, T.J., "Aircraft Nose Gear Shimmy Studies", Proceedings of the SAE Aerospace Atlantic Conference and Exposition, Dayton, Ohio, April 20-23, 1993.

58. Krabacher, William E., "The Experimental Measurement of the T-46 Nose Landing Gear Shimmy Parameters", Proceedings of the Aerospace Atlantic Conference, Dayton, OH, May 1996.

59. Van Der Valk, R. and Pacejka, H.B., "An Analysis of a Civil Aircraft Main Gear Shimmy Failure", Vehicle System Dynamics, Vol. 22, No. 2, pp. 97-121, 1993.

60. Black, R. J., "Realistic Evaluation of Landing Gear Shimmy Stabilization by Test and Analysis", SAE Paper No. 760496, Business Aircraft Meeting, Wichita, Kansas, April 6-9, 1976.

61. Krabacher, W.E., "Aircraft Landing Gear Dynamics Present and Future", Proceedings of The SAE Aerospace Atlantic Conference and Exposition, Dayton, OH, April 20-23, 1993.

62. Kruger, W.; Besselink, I.; Cowling, D.; Doan, D.B.; Kortum, W.; and Krabacher, W., "Aircraft Landing Gear Dynamics: Simulation and Control", Vehicle System Dynamics, Vol. 28, No.2-3, pp.119-158, 1997. 


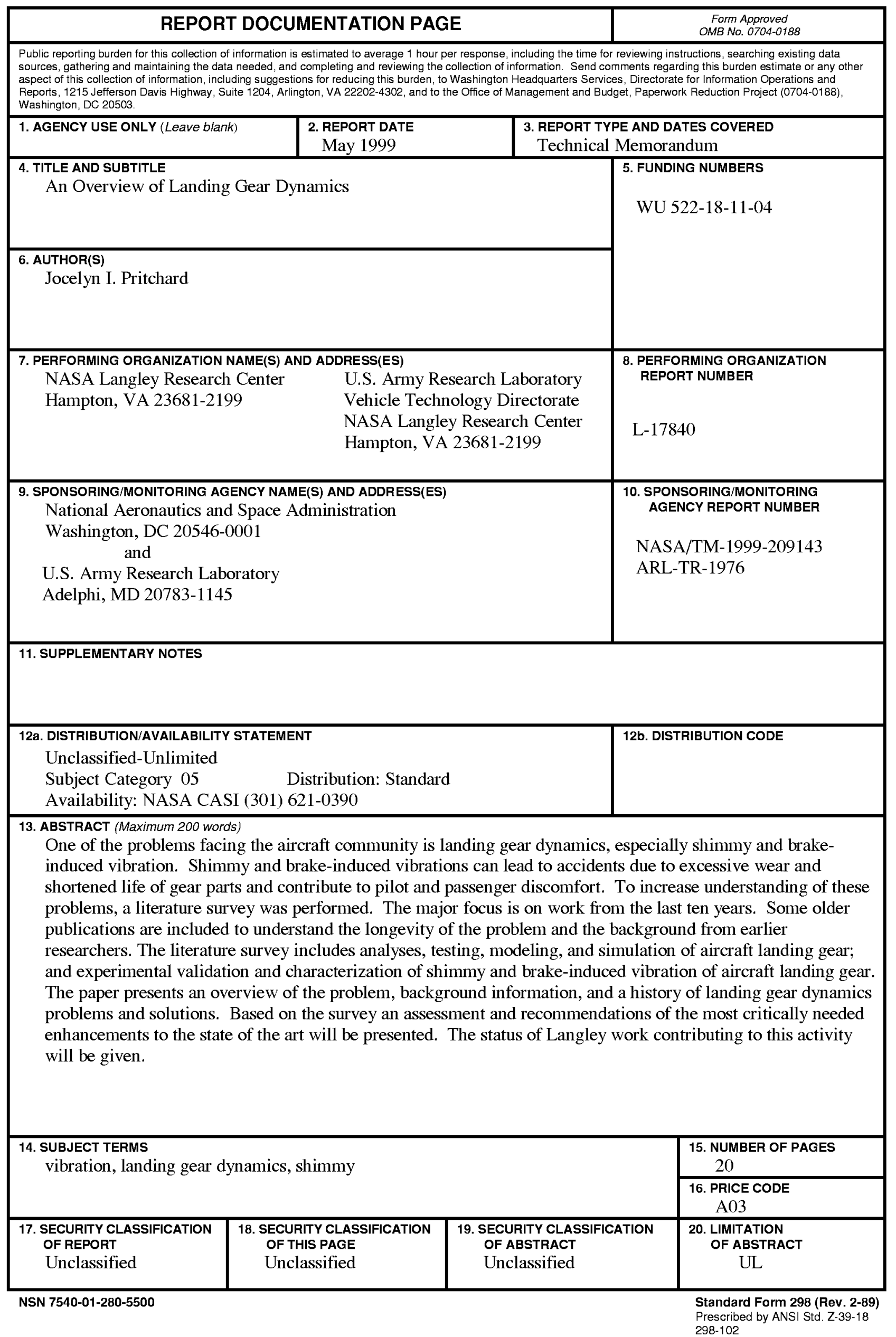

